\title{
O poder de narrar: geopolítica da distribuição cinematográfica no Brasil
}

\author{
The power of tell: geopolitics of cinematographic distribution at \\ Brazil
}

Renata Rogowski Pozzo*

\section{RESUMO}

O presente ensaio desenvolve uma investigação dentro do campo da economia política da cultura que objetiva problematizar e desvendar caminhos para o entendimento do quadro de hegemonia do cinema hollywoodiano no Brasil, tendo como foco a distribuição em salas. Coloca-se como hipótese que o subdesenvolvimento econômico do cinema nacional tem origem em questões de ordem macroeconômica, a saber, na estrutura oligopolista da indústria cinematográfica em escala mundial que logrou a dominação do mercado, especialmente da esfera da distribuição, pelas majors. À luz do que escreve Ellen Wood sobre o imperialismo contemporâneo, opera-se com as ideias de tríade competitiva de Alfred Chandler, centralização do capital de Harry Braverman e mundialização do capital de François Chesnais, para entender a estrutura e a organização contemporânea das grandes corporações de mídia. A partir de dados publicados pelo Observatório Brasileiro do Cinema e do Audiovisual (OCA-ANCINE), analisa-se a atuação das distribuidoras estrangeiras no Brasil, bem como dois movimentos contemporâneos que reconfiguram o mercado: a digitalização das salas e a emergência do streaming.

Palavras-chave: Economia Política do Cinema; Distribuição Cinematográfica;

\begin{abstract}
This essay develops an investigation inside political economy of culture field aiming to problematize and unveil ways to understand the Hollywood cinema hegemony in Brazil, focusing on distribution in movie theaters. We hypothesize that the Brazilian cinema economic underdevelopment has its origin in macroeconomic issues, namely, in the film industry oligopolistic structure on a world scale that has achieved market domination, especially in the sphere of distribution, by the majors. Observing what Ellen Wood writes about contemporary imperialism, we operate with the ideas of the competitive triad of Alfred Chandler, centralization of the capital of Harry Braverman and globalization of the capital of François Chesnais, to understand the structure and contemporary organization of the great media corporations. Based on data published by the Brazilian Cinema and Audiovisual Observatory (OCA-ANCINE), we analyzed the performance of foreign distributors in Brazil, as well as two contemporary movements that reconfigure the market: the digitalization of theaters and the emergence of streaming.
\end{abstract}

Kewords: Cinema Political Economy; Cinematographic Distribution; Culture and Imperialism; Brazilian Cinema.

\footnotetext{
* Doutora em Geografia pela Universidade Federal de Santa Catarina (UFSC). Professora do Curso de Arquitetura e Urbanismo e do Programa de Pós-graduação em Planejamento Territorial e Desenvolvimento Socioambiental da Universidade do Estado de Santa Catarina (Udesc). Endereço: Rua Coronel Fernandes Martins, 270. CEP: 88790-000, Laguna, SC. Telefone: (48) 3647 7900. E-mail: renata.pozzo@udesc.br.
} 


\title{
INTRODUÇÃO: O PODER DE NARRAR
}

\begin{abstract}
"O poder de narrar, ou de impedir que se formem e surjam outras narrativas, é muito importante para a cultura e o imperialismo, e constitui uma das principais conexões entre ambos". (SAID, 2011, p. 11).
\end{abstract}

Em 1960, Paulo Emílio Sales Gomes, importante historiador e crítico de cinema, publicou um texto intitulado "Uma situação colonial?". Neste texto, tratou sobre a dominação cultural estadunidense como uma forma de colonialismo praticado contra - Brasil, que, argumentava ele, seria um país "ocupado" por corporações internacionais (GOMES, 1981).

A primeira denúncia pública desta situação cinematográfica colonial partiu de Humberto Mauro, em 1925: "Denunciava Mauro a falta de empenho das distribuidoras estrangeiras quando se trata de distribuir o filme nacional" (CAPOVILLA, 1963). Avaliações como esta se intensificaram a partir dos anos 1960, no contexto da Primeira Convenção Nacional da Crítica Cinematográfica, realizada em São Paulo, na qual se propunha "assumir atitude clara e definida face aos problemas que sufocam a nossa indústria, esforçando-se no sentido de libertar o Brasil de sua condição de país cinematograficamente subdesenvolvido" (CAPOVILLA, 1963).

De fato, isso que Paulo Emílio chamou de ocupação condiz com a formas indiretas de dominação imperialista na contemporaneidade, que se realizam para além do militarismo, por mecanismos preponderantemente econômicos, mas também políticos e culturais. Este colonialismo a que se refere Paulo Emílio, trata-se de um processo de conquista da hegemonia engendrado a partir da competitividade estrutural de empresas que se formaram conjuntamente com a fase monopolista do capitalismo mundial. Evidentemente, estas empresas estiveram e estão amparadas por atores políticos e ideológicos.

Wood (2014), argumenta que foi através da manipulação de mecanismo econômicos que os Estados Unidos tornaram-se a grande potência imperialista do capitalismo no século XX. Sua dominação estende-se por várias instâncias da sociedade, inclusive as imagens, em grande medida determinando o que é exibido em nossas telas de cinema, por exemplo. A indústria cinematográfica cumpre um duplo papel em relação ao imperialismo americano, pois além de movimentar valores importantes no plano econômico, atua como agente ideológico.

Esta relação fica evidente quando atenta-se para a insistente produção e distribuição de filmes estadunidenses de ação com temática de guerra no mercado brasileiro e mundial. O maior público de cinema registrado no Brasil até os dias atuais foi para o filme "Vingadores: Guerra Infinita". Distribuído pela Disney, foi assistido por 14,5 milhões de brasileiros em 2018 (ANCINE, 2019). Para o modo capitalista de imperialismo econômico estadunidense, a dominância do poder militar é mais importante no sentido de demonstração de força, de prevenir e evitar ataques, do que para efetivamente ser utilizado: "Então a primeira premissa da doutrina militar norte-americana, cujas raízes datam do final de Segunda Guerra Mundial, é que os Estados Unidos têm de ter tamanha superioridade militar que nenhuma outra potência, amiga ou inimiga, sequer tentaria desfiar ou igualar sua hegemonia global ou regional" (WOOD, 2014, p.10). Neste sentido, o cinema vem sendo historicamente 
utilizado como forma de propaganda de sua capacidade militar. Tal como afirma Virilio (2005, p. 24), "A guerra não pode jamais ser separada do espetáculo mágico, porque sua principal finalidade é justamente a produção deste espetáculo: abater o adversário é menos capturá-lo do que cativá-lo, é infringir-lhes, antes da morte, o pavor da morte".

O cinema fruto das grandes produções das majors, em seus vários gêneros e formatos, domina as salas de exibição de todo mundo; mas nem sempre foi assim. A projeção de filmes comerciais teve início no final do século XIX na França, que manteve o domínio do mercado internacional até a Primeira Guerra Mundial. Com o início da guerra, França, Itália, Grã-Bretanha e Alemanha reduziram drasticamente sua produção e os EUA passaram a dominar os mercados europeu, latino-americano e japonês (SIMIS, 1996). O crescimento da indústria estadunidense neste período foi vertiginoso: ao final da Primeira Guerra já produziam $85 \%$ dos filmes exibidos em todo mundo e $98 \%$ dos exibidos na América Latina, causando uma revolução na estrutura da produção cinematográfica mundial, como demonstra Turner (1997, p. 24):

Antes, a produção de filmes, sua distribuição para as salas de projeção e o gerenciamento destas salas eram feitos por empresas distintas. À medida que crescia o domínio norte-americano, tornava-se evidente que o controle sobre a indústria cinematográfica podia ser assegurado se uma companhia produzisse, distribuísse e exibisse seus próprios filmes.

Este sistema industrial de produção cinematográfica inventado pelos Estados Unidos é o chamado Sistema de Estúdio, ou sistema de Integração Vertical. Caracteriza-se pela participação de uma mesma empresa em todas as etapas da cadeia produtiva de um filme: produção, distribuição e exibição. Esse modelo não se dissolve com o estabelecimento das plataformas de streaming, pelo contrário: hoje, por exemplo, a Netflix é a principal produtora dos filmes que distribui/exibe.

A hegemonia do sistema de estúdio hollywoodiano solidificou a distribuição como o eixo central da cadeia produtiva do cinema, ao fazer a mediação entre os extremos da produção e da exibição. Como constatam Fagundes e Schuartz (2003), na indústria cinematográfica brasileira, ao contrário dos EUA, excetuando-se experiências como a criação da Distribuidora da EMBRAFILME nos anos 1970, ou a Globo Filmes atualmente, predomina a separação entre estes três circuitos. Além disso, a distribuição de filmes dentro do território nacional é dominada por empresas de capital estrangeiro.

Segundo Bernardet (2009), a presença agressiva no mercado interno do cinema estrangeiro limita as possibilidades de afirmação de uma cinematografia nacional e condiciona grande parte de suas formas de expressão. Neste sentido, percebe-se que o público do cinema nacional está concentrado em filmes que seguem os moldes narrativos do cinema comercial estadunidense: "A recepção dos filmes nacionais tem de ser medida a partir de um olhar sobre um público/crítica que assiste a um número muito maior de filmes estrangeiros que brasileiros." (MENDONÇA, 2007, p. 59). Para continuar na temática militar, basta lembrar do sucesso de Tropa de Elite 2, visto por mais de 11 milhões de brasileiros em 2016 (ANCINE, 2019). Apesar da euforia do crescimento de público para o cinema nacional desde a segunda metade da década de 1990, com a Retomada, passando pelos anos 2000, principalmente para os filmes produzidos pela Globo Filmes, o pano de fundo deste crescimento é a ocupação do mercado nacional pelo capital internacional em toda sua cadeia (Gráfico 1). 
Gráfico 1 - Público em milhões para filmes brasileiros e estrangeiros entre 1971 e 2018.

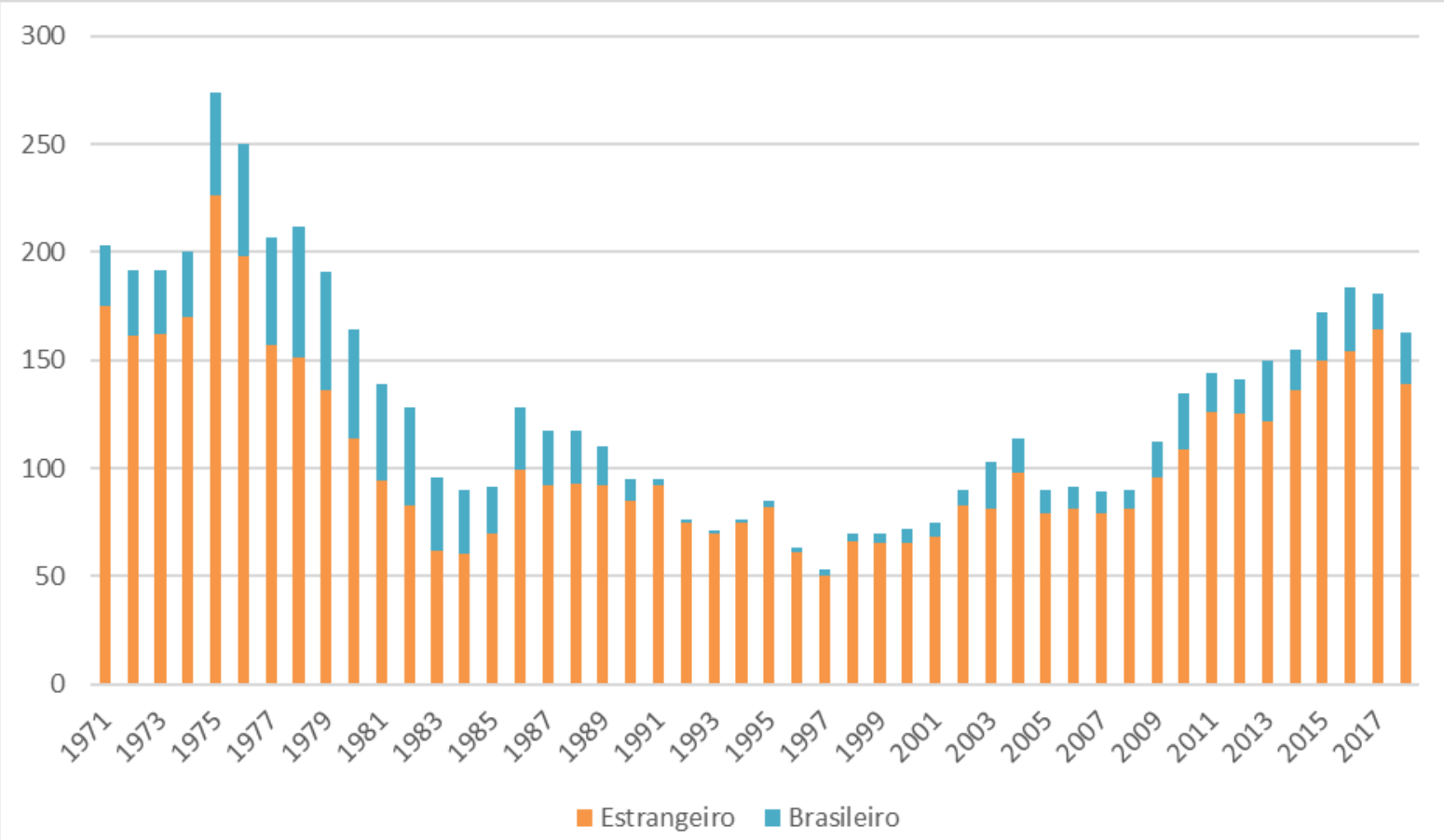

Fonte: FilmeB; ANCINE, 2019. Elaborado pela autora.

Diante deste cenário, o presente ensaio desenvolve uma investigação dentro do campo da economia política da cultura que objetiva problematizar e desvendar caminhos para o entendimento do quadro de hegemonia do cinema hollywoodiano no Brasil'. Tem foco na distribuição da produção cinematográfica de longasmetragens de ficção para exibição em salas de cinema. À luz do que escreve Ellen Wood (2014) sobre o imperialismo contemporâneo, opera-se com as ideias de tríade competitiva de Alfred Chandler (1998), centralização do capital de Harry Braverman (1987) e mundialização do capital de François Chesnais (1996), para entender a estrutura e a organização contemporânea das grandes corporações de mídia. A partir de dados publicados pelo Observatório Brasileiro do Cinema e do Audiovisual (OCAANCINE), analisa-se a atuação das distribuidoras estrangeiras no Brasil, bem como dois movimentos contemporâneos que reconfiguram o mercado: a digitalização das salas e a emergência do streaming.

Coloca-se como hipótese para esta investigação que, apesar das justificativas para o "insucesso industrial" do cinema nacional recaírem frequentemente na questão da qualidade dos filmes (ou seja, na esfera da produção), na falta de público, na legislação etc., nosso problema real é de ordem socioeconômica, mais especificamente, a dominação por parte das majors da distribuição do cinema no país. Ou seja, o subdesenvolvimento histórico do cinema nacional tem origem em questões de ordem macroeconômica, na estrutura oligopolista da indústria cinematográfica em escala mundial.

\footnotetext{
${ }^{1} \mathrm{O}$ artigo é parte da tese de doutorado defendida em 2015 junto ao Programa de Pós-graduação em Geografia da Universidade Federal de Santa Catarina, intitulada "Uma Geografia do Cinema Brasileiro: bloqueios internacionais, contradições internas", sob orientação do Prof. Marcos Aurélio da Silva.
} 


\section{ECONOMIA POLÍTICA DO CINEMA: AS CORPORAÇÕES DE MÍDIA E AS MAJORS}

A indústria cinematográfica estadunidense poderia ser representada por um triângulo em que na ponta estão as majors (Paramount, Warner, Universal, Disney/Fox e Columbia), no meio as médias, muitas delas já controlados pelas majors (MGM, Dreamworks, New Line, Miramax) e na base as produtoras e distribuidoras menores, com frequência independentes, enfrentando constantes dificuldades. Sem a participação das majors, a distribuição de um filme independente é problemática (WASKO, 2007) e, evidentemente, os filmes estrangeiros encontram grande dificuldade para entrar nas salas americanas.

Os estúdios associados à MPAA ${ }^{2}$ controlam $75 \%$ do mercado mundial de distribuição. Eles praticamente escolhem o que vamos assistir e trabalham inclusive em esquemas de "arranjos de distribuição" através, por exemplo, da United Internacional Pictures (UPI) que atua nos mercados nacionais distribuindo em pacote filmes da Paramount, Universal e MGM. (WASKO, 2007). No cenário brasileiro, entre 2009 e 2018, os EUA dominaram cerca de $80 \%$ das bilheterias das salas de cinema (ANCINE, 2019).

Segundo Braverman (1987, p. 220), "as bases para a teoria da empresa monopolista foram lançadas por Marx, quando ele analisou a tendência do capital a aglomerar-se em imensas unidades", já no final do século XIX. A concentração do capital seria o primeiro processo característico desta fase, dizendo respeito à formação de economias de escala. Já a centralização ocorre em uma etapa superior, a partir da "expropriação do capitalista pelo capitalista". É neste momento que surgem as grandes empresas modernas, quando "se desfaz o vínculo direto entre o capital e seu proprietário individual".

A centralização prevê uma integração em dois sentidos, vertical e horizontalmente:

Assim é que, pelo crescimento e pela combinação, a empresa fabril adquire instalações para produção de matérias primas, transporte, instituições semibancárias para aumento do capital ou ampliação do crédito etc. Ao mesmo tempo, a integração horizontal reúne uma variedade de produtos sob a égide de um único agregado de capital, às vezes reunido sob o controle financeiro geral produtos $e$ serviços que não exibem relação visível uns com os outros, exceto em sua função como fonte de lucro. (BRAVERMAN, 1987, p. 225226).

Seguindo os passos de Braverman (1987), chega-se ao que Chandler (1998) descreve como Economias de Escala e Escopo. À formação das economias de escala seguiramse as economias de escopo, que Chandler (1998, p. 308) define como "economias de produção ou distribuição conjunta".

Como resultado desta estruturação ao mesmo tempo concentrada (integração vertical) e descentralizada (integração horizontal), a administração ganha papel de destaque. Entre os controles administrativos, o que mais se destaca neste processo é a tentativa de "redução do caráter autônomo da demanda de seus produtos e aumentar o caráter induzido" (BRAVERMAN, 1987, p. 227), ou seja, a etapa da distribuição (que engloba também as estratégias mercadológicas) adquire cada vez mais importância na cadeia produtiva.

\footnotetext{
${ }^{2}$ Motion Picture Association of America, associação que representa os cinco maiores estúdios de Hollywood, a qual associou-se recentemente a Netflix.
} 
As economias de escopo na produção e na distribuição são a essência dos processos de integração, em que o setor de distribuição integrado passou a garantir a escala na produção: "Ter um setor de vendas tornou-se o meio mais seguro de conquistar e manter uma fatia de mercado suficientemente grande para garantir vantagens de custos em função da escala". (CHANDLER, 1998, p. 323).

A principal forma pela qual os grandes estúdios hollywoodianos conquistaram o mercado mundial foi através de uma competitividade estrutural, construída a partir do estabelecimento da tríade competitiva (CHANDLER, 1998) entre produção, distribuição e gerência, com apoio do Estado Nacional, mas, fundamentalmente, a partir de sua integração com o capital financeiro e do desenvolvimento do conhecimento técnico ${ }^{3}$.

Chesnais (1996) aponta para as 3 principais características de uma empresa multinacional contemporânea:

a) A origem nacional da empresa multinacional e o cordão umbilical que é mantido com este Estado;

b) Conseguinte a esta origem nacional, a grande empresa é o resultado de longos e complexos processos de concentração e centralização e, "frequentemente diversificou-se antes de internacionalizar" (CHESNAIS, 1996, p 73);

c) A grande empresa apresenta-se como um grupo que "atua em escala mundial e tem estratégias e uma organização estabelecidas para isso". (CHESNAIS, 1996, p. 73).

Até os anos 1980, ainda segundo Chesnais (1996), as principais estratégias exercidas pelas multinacionais eram as de aprovisionamento (integração vertical com interesse em recursos primários presentes nos países da periferia), de mercado (distribuição) e de produção racionalizada (produção integrada internacionalmente); porém a partir de então surgiria uma nova estratégia que caracteriza a grande empresa contemporânea: a técno-financeira: "O tamanho e os meios organizacionais indispensáveis ao domínio das informações necessárias para atuar nos mercados mundializados apresentam-se, assim, como elementos inerentes à existência desses mercados". (CHESNAIS, 1996, p. 103). Esta estratégia técno-financeira é motor da expansão dos grupos no exterior e está baseada na capacidade tecnológica da empresa para administrar operações complexas e no know-how adquirido até então: "Com isso, tenderá a sair do seu setor de origem e diversificar-se em modalidades totalmente originais." (MICHALET, 1985, p. 60 apud CHESNAIS, 1996, p. 77).

Assim, os grupos passam a se integrar e a fundir-se através de aquisições majoritárias e minoritárias, formando redes de investimento. A grande empresa cresce e se fortalece, já que inaugura a possibilidade de se apropriar de valores fora das fronteiras materiais da companhia. Neste sentido, Chesnais (1996) aponta que justamente na década em que começam a aparecer estas multinacionais de "novo

\footnotetext{
${ }^{3}$ Chandler (1998, p. 305) destaca o papel dos executivos na conceituação da grande empresa moderna, sendo esta definida como "um conjunto de unidades operacionais, cada qual com suas instalações e seu quadro de pessoal, cuja totalidade de recursos e atividades é coordenada, monitorada e alocada por uma hierarquia de executivos de segunda e primeira linhas."
} 
estilo" (com estratégias técno-financeiras ${ }^{4}$ ), a dimensão dos grandes grupos aumenta, e seus investimentos cruzados garantem que estes saiam quase ilesos da crise de 1973. Nesta rede, as indústrias de comunicação têm papel central, considerando que a posição dos Estados Unidos como economia nacional dominante está também relacionada à formação de sua hegemonia cultural:

\begin{abstract}
O sonho projetado mundialmente a partir de Hollywood ou de Anaheim (a cidadezinha da Califórnia onde fica a sede do grupo multinacional Disney) é o do capitalismo e da mercantilização total das atividades humanas, sua aspiração e tendência. Dele se beneficiam, em consequência, todas as multinacionais, bem como o conjunto das forças sociais comprometidas com a extensão e consolidação da influência do capitalismo em todo planeta. (CHESNAIS, 1996, p. 120).
\end{abstract}

De acordo com Arsenault e Castells (2008), atualmente, a indústria cultural se organiza em torno de redes globais de corporações multimídia que conectam grandes empresas nacionais a empresas menores, regionais ou locais, nas mais diversas partes do globo. A estas empresas locais cabe a função de "customizar" o produto global de acordo com as demandas do lugar. Trata-se, segundo os autores, de uma intensa dialética de globalização/diversificação em que o capital global mascara-se com uma identidade local: uma simples pluralidade numérica substitui a diversidade genuína. Mesmo havendo algumas ilhas de produção nacional independente, de acordo com Arsenault e Castells (2008), hoje a grande maioria das emissoras nacionais dos países periféricos faz parte das redes de negócios das grandes corporações.

Mais do que isso, o sucesso de uma companhia depende, em grande medida, de sua capacidade de conectar-se a estas redes. O que se estabelece então, é uma estrutura de oligopólio que convive com pequenas corporações de forma integrada (BOLAÑO, 2010).

Segundo Harvey (1992, p. 150),

O incremento da capacidade de dispersão geográfica de produção em pequena escala e de busca de mercados de perfil específico não levou necessariamente, no entanto, à diminuição do poder corporativo. Com efeito, na medida em que a informação e a capacidade de tomar decisões rápidas num ambiente deveras incerto, efêmero e competitivo se tornam cruciais para os lucros, a

\footnotetext{
${ }^{4}$ Segundo Chesnais (1996, p. 212), a organização do sistema mundial de intercâmbio contemporâneo "é resultante da interação combinada de Estados e dos principais agentes da economia capitalista, que são hoje os grupos industriais e os grandes bancos, atuando em resposta à pressão de um conjunto de oportunidades (de lucro) e de obrigatoriedades: econômicas, políticas e também tecnológicas". Diante do quadro político do neoliberalismo, ou seja, de liberalização e desregulamentação da economia, as grandes empresas e, principalmente, as instituições financeiras erguem-se com uma força poderosa perante os Estados, as empresas menores e os grupos sociais despossuídos (CHESNAIS, 1996). A partir dos anos 1980, segundo o mesmo autor, o imbricamento entre capital produtivo e financeiro é destacado no cenário da formação das redes de empresas, momento em que as instituições financeiras (liberalizadas e mundializadas) passaram a intermediar diretamente as operações internacionais de aquisições e fusões. As grandes corporações modernas caracterizam-se atualmente, portanto, também por sua ligação com o capital financeiro. Este processo de financeirização da produção, de fato iniciado a partir da crise de 1973/74, aprofunda-se na década de 1980 e é estendido à América Latina na década de 1990 (SILVA, 2004).
} 
corporação bem organizada tem evidentes vantagens competitivas sobre os pequenos negócios.

Graças às possibilidades oferecidas pela modernização tecnológica ${ }^{5}$ no ramo das comunicações, a "tensão que sempre existiu no capitalismo entre monopólio e competição, entre centralização e descentralização de poder econômico, está se manifestando de modos fundamentalmente novos". (HARVEY, 1992, p. 151). Ocorre, neste processo, o crescimento da "interligação de firmas supostamente rivais de origem nacional distinta". (HARVEY, 1992, p. 160).

Este processo de concentração que induz a uma crescente desnacionalização da produção e distribuição de mídia nos países periféricos é face de um processo maior levado a cabo a partir dos anos 1970 e conduzido pela ideologia neoliberal: "Multinacionais gigantes da mídia, como a Time Warner e a News Corp são simultaneamente produtos e agentes de tendências maiores de desregulamentação, corporatização e da digitalização das comunicações." (ARSENAULT; CASTELLS, 2008 - Tradução da autora).

O conteúdo técnico do estabelecimento deste poder corporativo tem extrema importância. As corporações em processo de concentração e conglomeração beneficiam-se da digitalização das comunicações, que favorece a formação de redes de negócios globais. Por este motivo o comportamento das corporações de mídia está associado ao das corporações da internet. Assim a concentração vai aumentando, pois apenas empresas de grande porte têm capital para realizar imediatamente os investimentos necessários a esta transição tecnológica para o digital. Bernardet (2009) já apontava no final da década de 1970 que esta concentração está baseada "na reorganização que, nas últimas décadas, sofreram as produtoras cinematográficas americanas a sua absorção por grandes corporações.[...] Umas das consequências desse sistema é que a política cinematográfica pode obedecer a injunções que nada tem a ver com cinema."

Arsenault e Castells (2008), ao estudarem as maiores corporações de mídia do mundo (as Big 7: Time Warner, Disney, News Corp, Bertelsmann, NBC - propriedade da General Eletric - CBS e Viacom), identificaram interessantes parcerias entre estas e as maiores companhias do ramo da internet e da comunicação digital (Google, Microsoft, Yahoo! e Apple). O estudo destas conexões revela como a propriedade dos meios de comunicação vem sofrendo um processo de concentração desde os anos 1970 (como apontava Bernardet).

Portanto, o processo de concentração econômica do setor de comunicações dá-se em dois sentidos:

a) Investimentos cruzados e parcerias: corporações competem e conspiram entre si.

b) Diversificação interna de mídia (integração horizontal): o que dá certo em uma plataforma é reposto para outra (TV/Satélite, Rádio/Música, Cinema, Impressa, Internet). Aqui insere-se a estratégia nomeada por Anderson

\footnotetext{
${ }^{5}$ Chandler (1998, p. 318-319) argumenta que "diferentes tecnologias de produção" têm "diferentes possibilidades de economias de escala e escopo", o que é comprovado pelo fato de que: "Somente quando se estabeleceram as modernas redes de transporte e comunicação - a ferrovia, o telégrafo, o vapor, o cabo submarino e as inovações organizacionais indispensáveis para operá-los como sistemas integrados - foi possível que os materiais fluíssem para a fábrica e os produtos acabados escoassem com rapidez e em volume suficientes para obter consideráveis economias de produção".
} 
(2006) de cauda longa, como uma reação de Hollywood às crises de bilheteria no início do século XXI. Passou-se a explorar ao máximo o potencial comercial de um filme de forma diversificada, inclusive pensando em sua distribuição para a emergente janela do streaming.

Segundo Arsenault e Castells (2008) a união destas duas tendências forma o que denominam de "Economias de Sinergia", que se define a partir da capacidade de conquistar economias de escala, diversidade de plataformas (economia de escopo, estratégia adotada também pelas empresas locais e regionais) e diversificação de conteúdos no serviço de expansão empresarial. Mesmo admitindo a ocorrência destas trocas entre empresas (muitas vezes do mesmo ramo, sendo a princípio concorrentes) parece-nos exagerado definir esta ordem como uma Economia de Sinergia, tal qual Arsenault e Castells (2008). Chesnais (1996, p. 93) destaca que mediante os investimentos cruzados os grandes grupos passam a conhecer melhor uns aos outros e o "espaço de rivalidade" delimita-se por relações de colaboração ("relações de dependência mútua de mercado"), mas principalmente de concorrência. Cabe destacar que a teia formada a partir destas relações de colaboração e concorrência tem a função primordial de barrar a entrada de outros grupos no oligopólio mundial. Ou seja, esta interação é estratégica:

O caráter oligopolista da concorrência implica a dependência mútua de mercado, bem como a instituição de formas combinadas de cooperação e de concorrência entre os 'verdadeiros rivais'. Não significa, de maneira alguma, que os grupos deixem de se entregar a uma rivalidade acirrada, muitas vezes encarniçada, chegando até a ser 'mortal'. A arena é mundial. (CHESNAIS, 1996, p. 117).

Os grandes estúdios responderam ao movimento de flexibilização da economia fortalecendo suas economias de escopo, diversificando a produção e explorando nichos de mercado, reduzindo o tempo de giro do consumo. A "nova integração vertical" é uma verticalização cruzada que se estabelece graças à estrutura horizontal formada entre os conglomerados.

\section{DISTRIBUIÇÃO CINEMATOGRÁFICA NO BRASIL CONTEMPORÂNEO}

O segmento de distribuição envolve promoção publicitária, criação dos trailers e toda a negociação com as janelas de exibição. O percurso para um filme nacional chegar às telas comerciais de exibição, que já era difícil, complicou-se ainda mais a partir dos anos 1990, quando as majors definitivamente hegemonizam-se atuando na distribuição (e exibição) cinematográficas em nosso país. Grande parte da produção cinematográfica brasileira não passa por distribuidores profissionais, sendo exibido unicamente em circuitos não comerciais e festivais, que, embora sejam de grande importância para circulação das obras de forma mais ampla e democrática no território nacional, não geram lucro para os produtores.

No caso brasileiro, as grandes distribuidoras Fox, Metro, Warner, Paramount, Universal, Disney e Sony vêm bloqueado os sistemas de produção internos do cinema brasileiro (produção, distribuição e exibição); excluíram e marginalizaram o país do sistema mundial de trocas - por isso nossos filmes dificilmente chegam ao mercado externo e sequer circulam satisfatoriamente no circuito nacional. A tabela abaixo mostra um comparativo entre o público e a renda dos títulos exibidos em 2018 nas telas brasileiras de cinema, com base no relatório sobre Distribuição em Salas da ANCINE (2019). 
Tabela 2 - Público e renda dos títulos exibidos no Brasil em 2018.

\begin{tabular}{lllllll}
\hline Título & Público & $\%$ & Renda & $\%$ & $\begin{array}{l}\text { Títulos } \\
\text { Exibidos }\end{array}$ & $\begin{array}{l}\text { Títulos } \\
\text { Lançados }\end{array}$ \\
\hline Brasileiros & $24 \mathrm{mi}$ & $15 \%$ & $290 \mathrm{mi}$ & $12 \%$ & 253 & 185 \\
Estrangeiros & $139 \mathrm{mi}$ & $85 \%$ & $2 \mathrm{bi}$ & $88 \%$ & 453 & 294 \\
\hline
\end{tabular}

Fonte: ANCINE, 2019. Adaptado pela autora.

Naquele ano, três majors juntas (Disney, Warner e Sony) agruparam $55 \%$ da renda total das bilheterias. Se adicionarmos a Universal e Fox, veremos que as cinco majors juntas concentraram $77 \%$ da renda de bilheteria em 2018. As 10 maiores distribuidoras atuantes no território brasileiro naquele ano, dentre as quais estão 4 nacionais (Paris, Downtown/Paris, Imagem e Diamond Films do Brasil), acumularam 98\% da renda total de bilheteria. Destaca-se que este cenário pouco mudou entre os anos de 2009 e 2018, período que compreende as análises da ANCINE.

Em relação ao público de cinema brasileiro, é importante destacar que, embora tenhamos uma quantidade considerável e cada vez maior de lançamentos, a bilheteria costuma estar concentrada em poucos títulos. Em 2018, por exemplo, apenas quatro filmes concentraram $75 \%$ do total de público (ANCINE, 2019).

A distribuição nacional de filmes brasileiros vem apresentando crescimento, passando da marca de 78\% da renda em 2009 para 98\% em 2018, destacando-se as distribuidoras Downtown/Paris, Imagem, Paris e Vitrine Filmes. A parceria brasileira Downtown/Paris esteve em evidência em 2018, ficando com $84 \%$ da receita total dos filmes nacionais, comercializando apenas 16 títulos. Foi responsável pela distribuição do filme Nada a Perder, que fez mais de 12 milhões de espectadores, maior público da história do cinema nacional. A distribuidora com maior número de filmes brasileiros exibidos em 2018 foi a Vitrine Filmes, com 55 obras. (ANCINE, 2019).

O relatório Distribuição em Salas da ANCINE referente a 2018 demonstra ainda que mesmo que o percentual de renda total das distribuidoras internacionais esteja em queda desde 2013 (passando de 30\% para 25\% em 2018), o valor absoluto da renda destas distribuidoras cresce, acompanhando a expansão de nosso parque exibidor que foi de 2678 para 3347 salas neste período, passando de R\$ 741 milhões em 2009 para $\mathrm{R} \$ 1,9$ bilhões em 2018. A renda das distribuidoras nacionais também cresceu, passando de $R \$ 225$ milhões em 2009 para $R \$ 606$ milhões em 2018. São elas que contribuem com a maior oferta de filmes no parque exibidor, chegando a representar $80 \%$ do número total de títulos exibidos em 2018 (568 filmes de distribuição nacional contra 138 filmes de distribuição internacional).

Mesmo com menos filmes na cartela, a presença massiva das distribuidoras estrangeiras no Brasil é responsável por cenários de ocupação predatória de salas por um único título, relatados com cada vez mais frequência. O filme Vingadores - Guerra Infinita, foi lançado simultaneamente em 90\% das salas brasileiras em 2018: ocupou 2938 das 3347 salas de cinema do país. 


\title{
TENDÊNCIAS CONTEMPORÂNEAS: A DIGITALIZAÇÃO DAS SALAS E 0 STREAMING
}

O processo de digitalização das salas de cinema e a emergência do streaming são dois movimentos contemporâneos que redesenham e, ao mesmo tempo, reafirmam a centralidade da distribuição para a estruturação da indústria cinematográfica mundial.

Até 2017, quando a digitalização do parque exibidor nacional deu-se por completo, a distribuição era discutida a partir da relação entre o número de cópias dos títulos e falava-se da dificuldade em distribuir rolos pesados de sensíveis filmes em um território tão grande como o brasileiro. Com a digitalização, reduziu-se o custo de produção de cópias, que podem ser armazenadas em pequenos e leves discos rígidos de fácil transporte e inclusive reutilizáveis, ou transmitidas via internet ou satélite.

Por imposição das distribuidoras, que deram prazo para a digitalização das salas de cinema sob o custo de não receberam mais seus filmes, o parque exibidor brasileiro encampou este processo. A nota técnica sobre distribuição satelital publicada pela ANCINE (2018) nos oferece uma amostra sobre o poder das distribuidoras enquanto promotoras de transições tecnológicas tão importantes:

\begin{abstract}
Reposição tecnológica é conceito chave para se entender a digitalização e, em especial, o fato de ter sido impulsionada pela iniciativa dos distribuidores. Em princípio, mesmo considerados o cinema $3 \mathrm{D}$ e outros elementos tratados adiante, a troca de equipamentos não é financiada ou motivada por serviços novos e novas receitas nos cinemas. Dessa forma, embora seja possível vislumbrar interesse genérico dos exibidores na digitalização por conta da facilitação e modernização dos mecanismos de distribuição, tais elementos não constituíam fatores suficientes para o autofinanciamento da atualização tecnológica em larga escala. Ou seja: da perspectiva do exibidor, a digitalização do sistema de projeção das salas em operação significava apenas custo adicional, por conta da obsolescência não planejada dos equipamentos analógicos em $35 \mathrm{~mm}$, tecnologia dominante desde o início do século XX. Ademais, no caso das novas salas, o processo demandava maiores investimentos do que os anteriores, haja vista os preços mais elevados dos projetores e servidores e de sua manutenção.
\end{abstract}

O aspecto tecnológico da dominação oligopolista se expressa de forma notável neste processo. Foram as majors que delinearam os chamados padrões $\mathrm{DCl}$, uma série de normas de uma arquitetura aberta para o cinema digital. $\mathrm{O}$ avanço das produções em 3D, especialmente a partir do sucesso de Avatar em 2009, quando este tipo de produção passou a aparecer com mais regularidade nas programações dos complexos de cinema, foi um grande impulso para a digitalização e modernização técnica das salas. Apesar de as distribuidoras terem assumido participação no financiamento da substituição dos projetores, em muitos países, como o Brasil, foi necessário financiamento estatal para viabilizar esta transição tecnológica.

A digitalização intensifica a presença do cinema das majors em nosso circuito, permitindo o lançamento de um mesmo título em um número ainda maior de salas, por isso casos como o relatado anteriormente são cada vez mais comuns. Um mesmo título atinge alto rendimento em um período muito menor, permitindo a entrada de outros lançamentos. Com isso, o cinema nacional perde cada vez mais espaço. 
Outro movimento que vem transformando a indústria do cinema, e nossa própria experiência com o cinema, trata-se da distribuição por streaming.

Durante todo este ensaio, tratou-se do cinema de forma tradicional: filmes de longametragem feitos para serem lançados em salas de cinema. Mas a verdade é que este modelo está em transformação. Hoje o cinema é pensado a partir de conteúdos que transitam por diversas plataformas, e o streaming deixa de ser visto como uma janela pós-lançamento (como era o home vídeo) e passa a figurar como janela de lançamento. Curiosamente, mesmo estando o comportamento das corporações de mídia associado ao das corporações de internet, elas não saíram na frente nessa corrida, atualmente liderada pela Netflix. Dentre as majors, a Disney anunciou o lançamento de sua plataforma de streaming em breve, entretanto, no momento os grandes estúdios ainda estão trabalhando no modelo de aluguel on line.

No ano de 2017, havia no Brasil 5,6 assinantes da Netflix. Os investimentos da Netflix são meticulosamente estudados com base nas informações de consumo dos usuários $^{6}$ - talvez por isso ela divulgue tão poucas informações sobre a audiência dos filmes. Em 2019, a distribuidora divulgou pela primeira vez informações sobre os dez filmes mais visualizados da plataforma. As visualizações vão de 73 milhões para Mistério no Mediterrâneo a 26 milhões para El Camino. Todos os dez filmes foram produzidos pela própria Netflix ou co-produzidos em associação com produtoras independentes.

\section{CONSIDERAÇÕES FINAIS: OCUPAÇÃO CULTURAL E O PAPEL DO ESTADO}

Para os intelectuais e artistas dos anos 1960/70, a identidade nacional e política do povo brasileiro, as raízes do Brasil e a ruptura com o subdesenvolvimento com base na intervenção do Estado eram questões centrais. Essas ideias foram aos poucos se diluindo sob efeito da ditadura, e, nos tempos atuais de mundialização do capital, elas voltam à tona (RIDENTI, 2000). Na contemporaneidade o papel do Estado é ressignificado. O Estado deve garantir a diversidade cultural, possibilitar a existência de pequenas, médias e grandes empresas no mercado. Assegurar um espaço para a articulação democrática entre a realidade local e os elementos universais como formadores da cultura, a dialética da diversificação e da uniformidade. Garantir, portanto, a sobrevivência dos criadores teimosos que estão presentes em todos os cantos do Brasil, para que se realizem "filmes que sejam capazes de mobilizar o público pela diferença e não pela imitação". (ESCOREL, 2005, p. 21). Nas palavras de Escorel (2005, p. 29):

Em última análise, parece evidente que o cinema brasileiro, para se consolidar, precisa ter uma função, uma necessidade, um papel social. Ele precisa ter uma presença efetiva no país e deixar de ser um evento esporádico, restrito a festivais, a filmes que são exibidos em circuitos ou salas de exibição consideradas "especiais" ou de "arte".

\footnotetext{
${ }^{6}$ Em janeiro foram anunciadas as indicações ao Oscar 2020, e a Netflix foi o estúdio com o maior número, 24. Na frente da Disney, com 23 e da Sony, com 20. Até o momento, era realizado o lançamento dos filmes em cinemas, muitas vezes de forma simbólica, para que estes pudessem concorrer a premiação. Foi assim, por exemplo, com O Irlandês, de Martins Scorsese em 2019. Entretanto, em função da pandemia de Covid-19 ocorrida em 2020, o Oscar anunciou que não mais exigiria o lançamentos dos filmes em salas de cinema.
} 
Mas a ação do Estado em defesa do cinema nacional não se restringe à política interna, necessitando amparar-se em uma visão sobre os bloqueios que ocorrem na ordem geopolítica internacional. Como explica Braverman (1987), o surgimento da grande empresa moderna se dá na passagem do século XIX para o XX e é marcado pela concentração e centralização dos processos e produtos. As corporações estadunidenses conquistam a hegemonia ao longo das primeiras décadas do século $\mathrm{XX}$, processo que tem em seu centro a competitividade estrutural das empresas, explicada mediante a teoria da tríade competitiva de Chandler (1998). No entanto, Amsden (2009) atenta que o desenvolvimento industrial nos países periféricos, ao contrário, não prescinde de um Estado, e um Estado forte.

Por sua vez, Chesnais (1996) vem demonstrar como estas grandes empresas se reestruturaram após a crise dos anos 1970, momento em que o mundo começou a encaminhar-se para o neoliberalismo. A estratégia foi o fortalecimento através do estabelecimento de redes de fusões intermediadas pelos bancos e possibilitadas pelas tecnologias da informação. Neste contexto, o papel do Estado em defesa da indústria nacional nos países periféricos é ainda mais urgente.

A este novo avanço das multinacionais nos anos 1970 (incluindo as cinematográficas), o Brasil respondeu com uma estratégia de substituição de importações, reforçando a Cota de Tela e criando a Embrafilme. Entretanto, ao novo momento do capitalismo mundial a partir dos anos 1990, com o avanço definitivo do neoliberalismo sobre os países periféricos, o Brasil não criou alternativas de produção da indústria nacional, o que culminou com a grande crise do cinema brasileiro na passagem dos anos 1980 para os anos 1990.

Tudo o que estudou-se sobre a formação das majors reflete-se de forma inversa quando analisada a indústria cinematográfica brasileira. O referido bloqueio internacional imposto pelas corporações de empresas modernas (e suas teias de investimento que impedem a entrada de novas empresas) é possível em virtude da baixa competitividade de nossas produtoras. Nosso setor de produção não é modernizado (não há a integração com o capital financeiro), o distribuidor é subdesenvolvido (setor, este, indispensável para a modernização industrial) e, por fim, nosso setor exibidor é deficiente em virtude de nossa rede urbana antidemocrática. Tal bloqueio se converte de causa para consequência de nosso subdesenvolvimento.

Ao mesmo tempo em que esta situação explica nosso insucesso econômico no mercado nacional e internacional (lembrando novamente a exceção da Globo Filmes que está integrada a rede de negócios das grandes corporações), esclarece a hegemonia mundial da indústria hollywoodiana. O poder das majors afirma-se, desta forma, hegemonicamente no globo por meio de uma competitividade estrutural.

Ainda, destaca-se que ao demonstrar os caminhos para o sucesso do cinema das majors, não há intenção de colocar este como um caminho único, possível e sequer recomendável. A pergunta é: devemos seguir algum modelo ou utilizar destas experiências para forjar nossas formas originais de desenvolvimento?

Há que existir espaço para ambos os cinemas brasileiros, para o migrante Zé Padilha que foi para a terra do Tio Sam dirigir Robocop, para os Globais que querem ser Hollywood, para o olhar especial dos recifenses e para aqueles que misturam de tudo um pouco. Todos os cinemas estão em uma unidade indissociável, não obstante, conflitiva. O conflito coloca-se justamente na luta pela hegemonia que, nos dias atuais, transita pelo eixo majors-Globo Filmes, e relega todos os outros olhares à 
marginalidade. A ideia de que há espaço para todos não oculta ingenuamente a certeza de que é preciso lutar por este espaço.

Artigo recebido em 02/02/2020 e aprovado em 23/04/2020.

\section{REFERÊNCIAS}

AMSDEN, Alice. A ascensão do resto: os desafios ao Ocidente de economias com industrialização tardia. São Paulo: Editora da UNESP, 2009.

ANCINE - Agência Nacional do Cinema. Distribuição em Salas - 2018. 2019. Disponível em:

<https://oca.ancine.gov.br/sites/default/files/repositorio/pdf/informe_distribuicao_em _salas_2018.pdf $>$. Acesso em 01/05/2020.

. Distribuição Satelital: Nota técnica. 2018. Disponível em: <Digitalização -

número de cópias l lucratividade /
https://oca.ancine.gov.br/sites/default/files/repositorio/pdf/distribuicao_satelital_not a_tecnica.pdf >. Acesso em 01/05/2020.

ANDERSON, Chris. A cauda longa. Rio de Janeiro: Elsevier, 2006.

ARSENAULT, Amelia H.; CASTELLS, Manuel. The Structure and Dynamics of Global

Multi-Media Business Networks. International Journal of Communication. 2008. Disponível em: <http://annenberg.usc.edu/Faculty/Communication\%2oand\%20Journalism/ /media/Glo balMultimediaBusinessNetworks.ashx>. Acesso em 10 jan. 2013.

BERNARDET, Jean-Claude. Cinema brasileiro: proposta para uma história. São Paulo: Companhia das Letras, 2009.

. Os Magros dias do cinema brasileiro. Revista Movimento, 14 de julho de 1975. Fonte: Acervo de Livros e Documentos da Cinemateca Brasileira. Biblioteca Paulo Emílio Sales Gomes. Acesso em janeiro de 2011.

BOLAÑO, Cesar. Economia política da comunicação e da cultura: breve genealogia do campo e das taxonomias das indústrias culturais. In: Economia da Arte e da Cultura. São Paulo: Itaú Cultural; São Leopoldo: Cepos/Unisinos; Porto Alegre: PPGCOM/UFRGS; São Cristóvão: Obscom/UFS, 2010.

BRAVERMAN, Harry. A empresa moderna. In: Trabalho e capital monopolista: a degradação do trabalho no século XX. Rio de Janeiro: LTC, 1987.

CAPOVILLA, Maurice. Cinema nacional: problema que o governo tem que resolver. Jornal Última Hora. 30 de setembro de 1963. Fonte: Acervo de Livros e Documentos da Cinemateca Brasileira. Biblioteca Paulo Emílio Sales Gomes.

CHANDLER, Alfred. Escala, escopo e capacidade organizacional. In: Ensaios para uma teoria da grande empresa. Rio de Janeiro: Editora Fundação Getúlio Vargas, 1998.

CHEASNAIS, François. A Mundialização do Capital. São Paulo: Xamã, 1996.

ESCOREL, Eduardo. Adivinhadores de água: pensando o cinema brasileiro. São Paulo: Cosac Naify, 2005. 
FAGUNDES, Jorge. SCHUARTZ, Luiz Fernando. Defesa da concorrência e a indústria do cinema no Brasil. Disponível em: www.culturalivre.org.br - Acesso em agosto de 2010.

GOMES, Paulo Emílio Sales. Uma situação colonial? In: Crítica de Cinema no Suplemento Literário. Rio de Janeiro: Paz e Terra, 1981.

HARVEY, David. A condição pós-moderna. São Paulo: Loyola, 1992.

MENDONÇA, José Luiz Riodade de. Cinema e Indústria: o conceito de modo de produção cinematográfico e o cinema brasileiro. Tese de Doutorado em Comunicação, USP, 2007.

RIDENTI, Marcelo. Em busca do povo brasileiro: artistas da revolução, do CPC à era da TV. Rio de Janeiro: Record, 2000.

SAID, Edward. Cultura e imperialismo. São Paulo: Companhia das Letras, 2011.

SILVA, Marcos Aurélio da. Globalização ou Formações Sociais Nacionais? Revista Ciência Geográfica. Bauru. V. 10, set. a dez. de 2004.

SIMIS, Anita. Estado e cinema no Brasil. São Paulo: Annablume; Fapesp, 1996.

TURNER, Graene. Cinema como prática social. São Paulo: Summus, 1997.

VIRILIO, Paul. Guerra e Cinema. São Paulo: Boitempo, 2005.

WASKO, Janet. Por que Hollywood é global?. In: MELEIRO, Alessandra (Org.). Cinema no mundo: indústria, política e mercado - Estados Unidos. São Paulo: Escrituras, 2007.

WOOD, Ellen. O império do capital. São Paulo: Boitempo, 2014. 